\title{
Diagnostic relevance of spatial orientation for vascular dementia A case study
}

\author{
Gillian Coughlan ${ }^{1}$, Emma Flanagan ${ }^{1}$, Stephen Jeffs ${ }^{1}$, Maxime Bertoux¹, \\ Hugo Spiers ${ }^{2}$, Eneida Mioshi ${ }^{3}$, Michael Hornberger ${ }^{1,4}$
}

\begin{abstract}
Spatial orientation is emerging as an early and reliable cognitive biomarker of Alzheimer's disease (AD) pathophysiology. However, no evidence exists as to whether spatial orientation is also affected in vascular dementia (VaD). Objective: To examine allocentric (map-based) and egocentric (viewpoint-based) spatial orientation in an early stage VaD case. Methods: A spatial test battery was administered following clinical and neuropsychological cognitive evaluation. Results: Despite the patient's complaints, little evidence of episodic memory deficits were detected when cueing was provided to overcome executive dysfunction. Similarly, medial temporal lobe-mediated allocentric orientation was intact. By contrast, medial parietal-mediated egocentric orientation was impaired, despite normal performance on standard visuospatial tasks. Conclusion: To our knowledge, this is the first in-depth investigation of spatial orientation deficits in VaD. Isolated egocentric deficits were observed. This differs from AD orientation deficits which encompass both allocentric and egocentric orientation deficits. A combination of egocentric orientation and executive function tests could serve as a promising cognitive marker for VaD pathophysiology.
\end{abstract}

Key words: spatial orientation, egocentric, allocentric, vascular dementia, VaD, executive function, neurodegeneration.

\section{RELEVÂNCIA DA ORIENTAÇÃO ESPACIAL PARA O DIAGNÓSTICO DE DEMÊNCIA VASCULAR: UM ESTUDO DE CASO}

RESUMO. A orientação espacial está emergindo como um biomarcador cognitivo precoce e confiável da fisiopatologia da doença de Alzheimer (DA). No entanto, não existe evidência de que a orientação espacial também seja afetada na demência vascular (DVa). Objetivo: Examinar a orientação espacial alocêntrica (baseada em mapas) e egocêntrica (baseada no ponto de vista) em um caso de DVa em fase incial. Métodos: Uma bateria de testes espaciais foi administrada após avaliação clínica e neuropsicológica cognitiva. Resultados: Apesar das queixas do paciente, poucas evidências de déficits de memória episódica foram detectadas quando foram fornecidas pistas para superar a disfunção executiva. Da mesma forma, a orientação alocêntrica mediada pelo lobo temporal medial estava intacta. Em contrapartida, a orientação egocêntrica mediada pela região parietal medial estava comprometida, apesar do desempenho normal em tarefas visuoespaciais padrão. Conclusão: Pelo nosso conhecimento, esta é a primeira investigação aprofundada dos déficits de orientação espacial na DVa. Foram observados déficits egocêntricos isolados. Isso difere dos déficits de orientação da DA que abrangem déficits de orientação alocêntricos e egocêntricos. Uma combinação de orientação egocêntrica e testes de função executiva poderia servir como um marcador cognitivo promissor para a fisiopatologia de DVa.

Palavras-chave: orientação espacial, orientação egocêntrica, orientação alocêntrica, demência vascular, função executiva, neurodegeneração.

$\mathrm{D}$ eficits in spatial orientation are an emerging early marker for Alzheimer's disease (AD) pathophysiology. ${ }^{1-5}$ They have

been strongly linked to medial temporal and intra-parietal regional changes in incipient and present $\mathrm{AD}$ pathophysiology. ${ }^{6,7}$ However,

This study was conducted at Norwich Medical School, University of East Anglia, Norwich, UK

${ }^{1}$ Norwich Medical School, University of East Anglia, Norwich, UK; ${ }^{2}$ nstitute of Behavioural Neuroscience, Department of Experimental Psychology, University College London, London, UK; ${ }^{3}$ School of Health Sciences, University of East Anglia, Norwich, UK; ${ }^{4}$ Dementia and Complexity in Later Life, Norfolk and Suffolk NHS Foundation Trust, Norwich, UK.

Michael Hornberger. Norwich Medical School, University of East Anglia, NR4 7TJ, Norwich, UK. Email: m.hornberger@uea.ac.uk

Disclosure: The authors report no conflicts of interest.

Received September 22, 2017. Accepted in final form February 01, 2018.

(c) BY 
at this stage it is not clear if vascular dementia patients also display any spatial orientation deficits. Such a distinction is important as vascular dementia $(\mathrm{VaD})$ is the second most common form of dementia and the diagnostic differentiation of both dementias is challenging with patients commonly complaining of generic memory complaints. ${ }^{8,9}$ Importantly, VaD patients often show intact medial temporal lobe function, while frontal and parietal regions are compromised due to white matter lesions in the superior frontal fasciculus. ${ }^{10,11}$ Therefore, apparent memory problems in $\mathrm{VaD}$ are more likely due to frontal executive and parietal visuospatial deficits than medial temporal memory mediated processes. In the current case study, we explored whether spatial orientation performance could help detect $\mathrm{VaD}$ and generate a different profile to $\mathrm{AD}$. We hypothesised that if the case shows spatial orientation deficits, these should be limited to egocentric parietal orientation problems but that allocentric medial temporal processes should remain intact.

\section{PARTICIPANT}

We report the case of RK, a 65-year-old married man, with six years of secondary education, who worked as a truck driver and window cleaner. A diagnosis of $\mathrm{VaD}$ was made in March 2017, he then presented at our dementia research clinic with memory complaints. $\mathrm{He}$ reported a short history of behavioural and psychological symptoms including apathy, depression and agitation/aggression. His medical history also revealed hypercholestrol, stage 2 hypertension, a BMI of 30 and life-long cigarette smoking. There was a strong family history of hypercholestrol (both parents and siblings) and heart disease-related death in both parents.

\section{Procedures}

RK underwent clinical and cognitive assessments, including neuropsychological assessments (Table 1). Both RK and his carer reported memory problems, such as misplacing keys and forgetting appointment. These issues are most likely due to attentional and executive demands, as recent family events were recalled without difficulty. Problems related to executive function, such as misplacing medication and poor finance management, were also reported. Importantly, spatial orientation difficulties were a central concern for both RK and the carer, and included complaints of disorientation on previously familiar routes and when using public transport, which had led to significant safeguarding concerns by the family. Based on these concerns, an additional spatial test battery was administered.

The spatial battery consisted of three spatial measures: The Supermarket task, The Statue task and the Clock test. The Supermarket task is an ecologically valid tool adopted to assess the integrity of egocentric and allocentric heading orientation and spatial memory in dementia. Participants are shown short video clips (7 seconds) of a virtual reality supermarket, whereby the person in the video is navigating from the entrance to a finishing location automatically (Figure 1). Once the video clip stops, participants are asked to indicate in real-life the direction of their starting point (egocentric
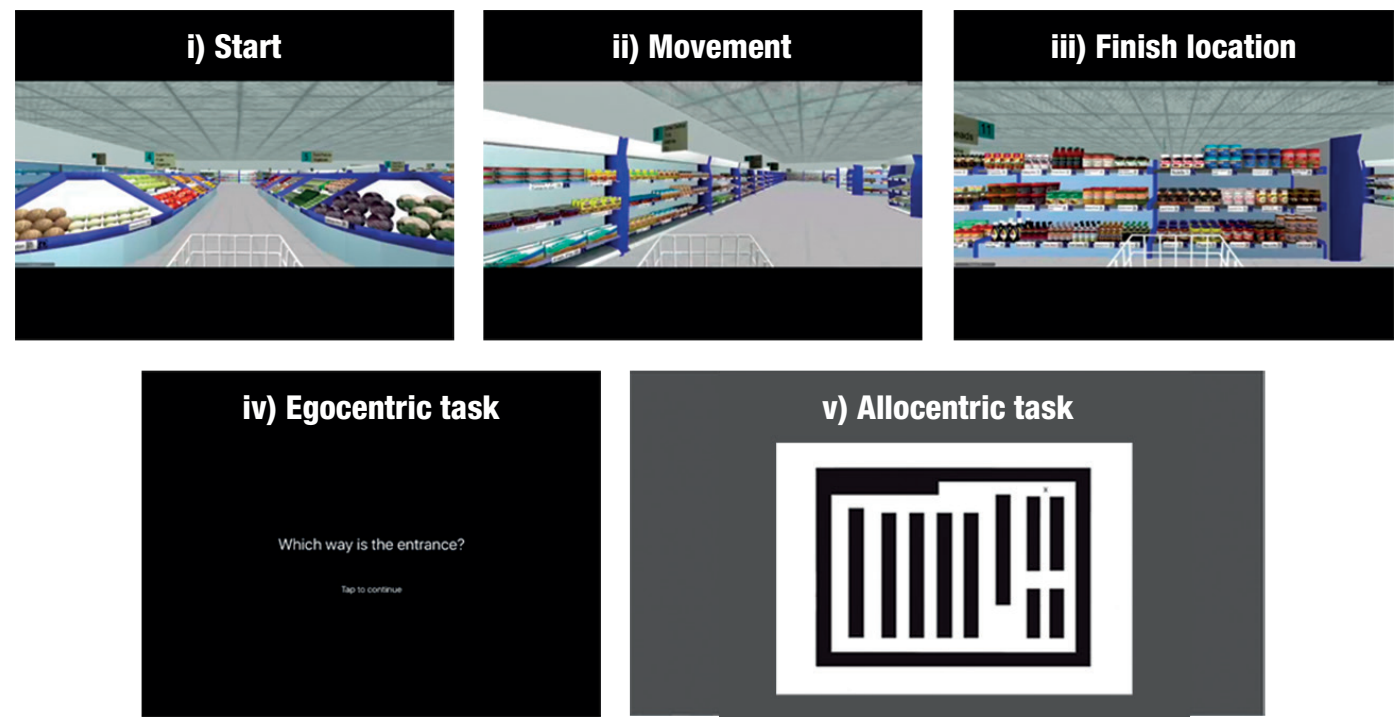

Figure 1. Screenshots from the Supermarket task, showing i) start viewpoint; ii) movement during an example video clip; iii) end location of an example video clip; iv) 'onscreen instructions prompting the participant to indicate the direction of their starting point'; v) the supermarket map participants use to indicate their finishing location and their heading direction when the video clip ends 
Table 1. Physical and neuropsychological background.

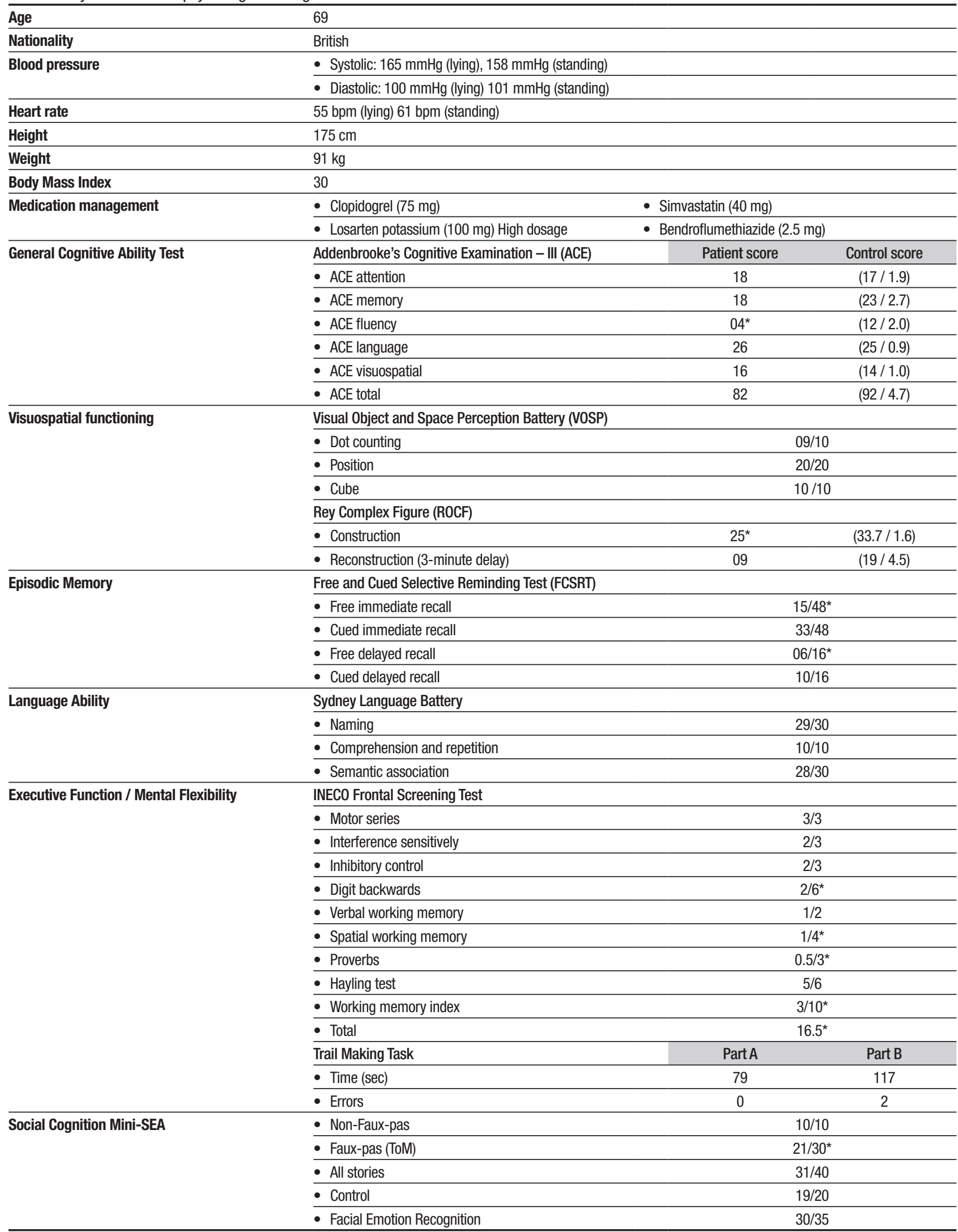

*Significant differences. Standard mean score and standard deviation representing an aged-matched control group are in parenthesis. Note control scores were only available for the ACE-III and the ROCF test. 

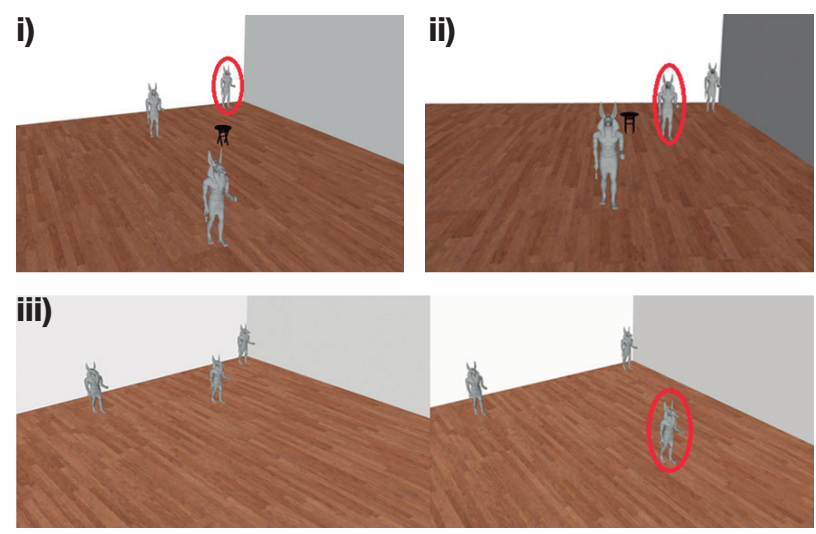

Figure 2. Screenshots from wall, stool and memory subtasks of the Statue test. Participants view images and are asked i) identify the statue closest to the wall (permanent landmark), ii) identify the statue closest to the stool (transient landmark), iii) identify which statue moved its location. Note, red circled figures are only shown for illustration purposes to identify the correct choice for each example, which was not shown to the participants.

orientation). In a second step, participants are given a map of the Supermarket and are asked to indicate where they are on the map (allocentric orientation) and what direction they are facing in the supermarket (heading orientation). More details can be found here. ${ }^{1,2}$

The Statue Test requires participants to make spatial judgements for a room with 3 statues and a small stool (Figure 2). Participants are asked to indicate i) the statue closest to one of the walls (permanent landmark); ii) the statue is closest to the stool (transient landmark); iii) which of the three statues moved its location after a delay. Each of these sub-tasks includes an easy, medium, and hard condition. The landmark decisions are thought to rely on intra-parietal lobes, whereas the memory condition is typically thought to rely on the medial temporal lobe.

The Clock test requires participants to imagine they are standing in the centre of a large clock facing, e.g., the number 12. Participants are asked to then point in reallife to different numbers on the clock face. For example, "Can you point to the number 9?" (Answer: pointing left). The questions increase in complexity across the test and require medial parietal mediated mental imagery, rotation and egocentric processes, with no episodic memory demand. The study was approved by the UK National Research Ethics Service (NRES: 16/LO/1366).

\section{RESULTS \\ Analysis}

We compared the case to a control sample $(N=13)$ with a mean age of $63(S D=4.8)$, who underwent similar testing. RK was contrasted against the controls via a modified paired sample t-test developed by Crawford and colleagues, ${ }^{12,13}$ resulting in a Z-case-control $\left(\mathrm{z}_{c c}\right)$ score as an interval estimate of the effect size.

\section{Neuropsychological evaluation (Table 1)}

RK achieved a score of 82 on the ACE-III, and cognitive deficits on free recall (immediate and delayed), executive function (spatial working memory, digital backwards, proverbs), social cognition and verbal fluency measures were observed. Importantly, on the FCSRT, his deficits were only present in free recall; once semantic cues were provided, RK could recall all verbal material, indicating executive dysfunction as the main contributor to the episodic memory deficits. Similarly, for visual episodic memory, the planning of the ROCF copy was disorganised due to executive deficits, which resulted in low recall score. RK's performance on the theory of mind (ToM) subset of the mini-SEA further suggests a partial deficit in social cognition. Importantly, basic visuo-perception and spatial discrimination (VOSP) were in the normal range, indicating no basic visual problems. Language skills were also in the normal range.

\section{Spatial orientation performance (Table 2)}

On the Supermarket task, RKshowed significant egocentric navigational impairments $\left(\mathrm{t}=-9.529, p<.000, \mathrm{z}_{\mathrm{cc}}=\right.$ -9.889), i.e. failing to point back to the starting point correctly. Similarly, heading orientation (correct judgement of facing direction after travel period) was also impaired, albeit less severely $\left(\mathrm{t}=-2.983, p=0.01, \mathrm{z}_{\mathrm{cc}}=\right.$ -3.095). By contrast, allocentric information, i.e. indicating the place location in the supermarket test, was not significantly different from the control group ( $t=$ $-1.537, p>0.05, z_{c c}=-0.206$ ).

On the statue task, RK showed no significant differences for performance on the easy and hard versions of all conditions, due to ceiling and floor effect. However, in the medium condition, abnormal scores were detected on both the wall $\left(\mathrm{t}=-3.085, p=0.01, \mathrm{z}_{\mathrm{cc}}=-3.160\right)$ and stool ( $\mathrm{t}=-2.590, p=0.02, \mathrm{z}_{c c}=-2.687$ ) condition only, showing deficits on visual judgements for permanent and transient objects. RK's memory performance was comparable to healthy controls.

Finally, the patient's clock test scores were significantly lower than those of controls $(\mathrm{t}=-2.965, p=0.01$, $z_{c c}=-3.077$ ) reflecting poor higher visual (mental rotation) and egocentric processing abilities.

\section{DISCUSSION}

To our knowledge, this is the first description of human spatial orientation deficits in a $\mathrm{VaD}$ case. As predicted, 


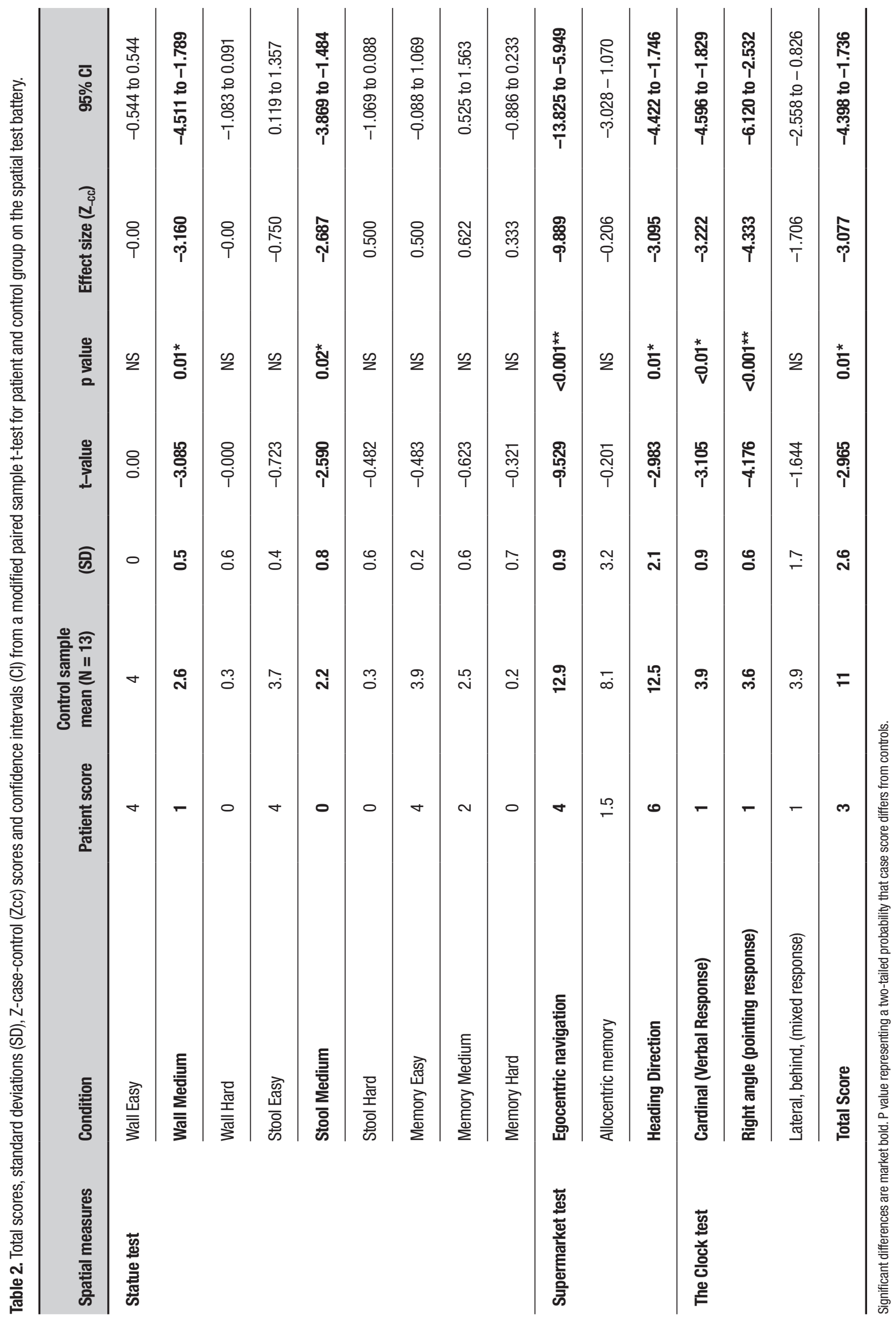


RK shows a typical neuropsychological profile of $\mathrm{VaD}$ that includes executive function impairments, as well as memory deficits indicating frontal lobe dependant executive symptomology. ${ }^{14,15}$ These deficits are accompanied by hypercholestrol, elevated BMI and stage 2 hypertension. ${ }^{16}$ Normal performance on allocentric orientation measures associated with the medial temporal lobe ${ }^{17-21}$ corroborate intact episodic memory after cueing. Deficits in egocentric orientation, dependent mainly on the medial parietal cortex, ${ }^{6,22,23}$ denote a clear and isolated spatial impairment. More specifically, RK performed worse than controls only on the egocentric portions of the spatial tasks. By contrast, standard neuropsychological visuospatial tasks failed to detect these spatial deficits, despite being one of RK's main symptoms which causing his family significant concern.

Diagnostically, patients with early AD disease usually exhibit both allocentric and egocentric deficits, ${ }^{1,2,5,24}$ while RK had specific egocentric difficulties. Therefore, detecting only egocentric deficits along with executive function impairments would not only suggest underlying $\mathrm{VaD}$ pathophysiology, but may also allow the diagnostic differentiation of $\mathrm{AD}$ from $\mathrm{VaD}$. This suggestion needs to be verified in future group and $\mathrm{AD}$ comparison studies. Nevertheless, findings reported here form a promising step towards advancing diagnostic tests for $\mathrm{VaD}$, for which cognitive testing is currently very limited and non-specific. ${ }^{25,26}$ More generally, spatial testing has a promising future as it is highly ecological, resulting in high patient test compliance but also involving very little verbal material. For these reasons, spatial tests are ideal for cross-cultural testing and are potentially less vulnerable to the impact of educational attainment.

Overall, we report a $\mathrm{VaD}$ case with selective egocentric spatial orientation deficits, which tap into the medial parietal changes that are typically associated with this condition. Spatial orientation therefore promises to complement executive testing in $\mathrm{VaD}$ to detect the underlying disruption of frontoparietal networks.

Author contribution. Michael Hornberger: design, analysis of data, intellectual contribution to the writing of the manuscript; Gillian Coughlan: design, analysis of data, intellectual contribution to the writing of the manuscript; Emma Flanagan, Stephen Jeffs, Maxine Bertoux, Hugo Spiers, Eneida Mioshi: data collection, intellectual contribution to the writing of the manuscript.

Grant support acknowledgement. This study was supported by FMH and MED funds of the University East Anglia.

Acknowledgements. We are grateful to the Ms Claire Rischmiller, Ms Kim Clipsham, Ms Zoe Inman, and Ms Michelle Hagon-Powley for their nurse support with the case.

\section{REFERENCES}

1. Tu S, Spiers HJ, Hodges JR, Piguet O, Hornberger M. Egocentric versus Allocentric Spatial Memory in Behavioral Variant Frontotemporal Dementia and Alzheimer's Disease. J Alzheimer's Dis. 2017; 59(3): 883-92.

2. Tu S, Wong S, Hodges JR, Irish M, Piguet O, Hornberger M. Lost in spatial translation - A novel tool to objectively assess spatial disorientation in Alzheimer's disease and frontotemporal dementia. Cortex 2015;67:83-94

3. Mokrisova I, Laczo J, Andel R, Gazova I, Vyhnalek M, Nedelska Z, et al. Real-space path integration is impaired in Alzheimer's disease and mild cognitive impairment. Behav Brain Res. 2016;307:150-8.

4. Laczó J, Andel R, Vyhnalek M, Vlcek K. APOE and spatial navigation in amnestic MCl: Results from a computer-based test. Neuropsychology 2014;28(5):676-84.

5. Serino S, Morganti F, Di Stefano F, Riva G. Detecting early egocentric and allocentric impairments deficits in Alzheimer's disease: An experimental study with virtual reality. Front Aging Neurosci. 2015;7:88.

6. Vlček, K, \& Laczó J. Neural correlates of spatial navigation changes in mild cognitive impairment and Alzheimer's disease. Front Behav Neurosci. 2014;8:89.

7. Delpolyi AR, Rankin KP, Mucke L, Miller BL, Gorno-Tempini ML. Spatial cognition and the human navigation network in $A D$ and $\mathrm{MCl}$. Neurology. 2007;69(10):986-97.

8. Looi JC, Sachdev PS. Differentiation of vascular dementia from AD on neuropsychological tests. Neurology 1999;53(4):670-8.

9. Attems J, Jellinger KA. The overlap between vascular disease and Alzheimer's disease - lessons from pathology. BMC Med. 2014;12(1): 206.

10. Heiss W-D, Rosenberg GA, Thiel A, Berlot R, de Reuck J. Neuroimaging

in vascular cognitive impairment: a state-of-the-art review. BMC Medicine 2016;14(1):174

11. Schuff N, Matsumoto S, Kmiecik J, Studholme C, Du AT, Ezekiel F, et al. Cerebral Blood Flow in Ischemic Vascular Dementia and Alzheimer's Disease By Arterial Spin Labeling MRI. Alzheimer's Dement. 2009;5(6):454-62.

12. Crawford JR, Garthwaite PH. Investigation of the single case in neuropsychology: confidence limits on the abnormality of test scores and test score differences. Neuropsychologia. 2002;40(8):1196-208.

13. Crawford JR, Garthwaite PH, Porter S. Point and interval estimates of effect sizes for the case-controls design in neuropsychology: Rationale, methods, implementations, and proposed reporting standards. Cogn Neuropsychol. 2010;27(3):245-60.

14. Kertesz A, Clydesdale S. Neuropsychological deficits in vascular dementia vs. Alzheimer's disease. Arch Neurol. 1994;51(12):1226-31.

15. McPherson SE, Cummings JL. Neuropsychological aspects of vascular dementia. Brain Cogn [Internet]. 1996;31(2):269-82.

16. Appleton JP, Scutt P, Sprigg N, Bath PM. Hypercholesterolaemia and vascular dementia. Clin Sci. 2017;131(14):1561-78.

17. Parslow DM, Rose D, Brooks B, Fleminger S, Gray JA, Giampietro V, et al. Allocentric Spatial Memory Activation of the Hippocampal Formation Measured With fMRI. Neuropsychology. 2004;18(3):450-61.

18. Feigenbaum JD, Morris RG. Allocentric versus egocentric spatial memory after unilateral temporal lobectomy in humans. Neuropsychology. 2004;18(3):462-72.

19. Jheng SS, Pai MC. Cognitive map in patients with mild Alzheimer's disease: A computer-generated arena study. Behav Brain Res. 2009; 200(1):42-7.

20. Iaria G, Palermo L, Committeri G, Barton JJS. Age differences in 
the formation and use of cognitive maps. Behav Brain Res. 2009; 196(2):187-91.

21. Hartley T, Lever C, Burgess N, O'Keefe J. Space in the brain: how the hippocampal formation supports spatial cognition. Philos Trans R Soc B Biol Sci. 2013;369(1635):20120510.

22. Vann SD, Aggleton JP, Maguire EA. What does the retrosplenial cortex do? Nat Rev Neurosci [Internet]. Nature Publishing Group; 2009; 10(11):792-802.

23. Spiers HJ, Barry C. Neural systems supporting navigation. Current Curr Opin Behav Sci. 2015;1:47-55.
24. Weniger G, Ruhleder M, Lange C, Wolf S, Irle E. Egocentric and allocentric memory as assessed by virtual reality in individuals with amnestic mild cognitive impairment. Neuropsychologia. 2011;49(3): 518-27.

25. Karantzoulis S, Galvin JE. Distinguishing Alzheimer's disease from other major forms of dementia. Expert Rev Neurotheory. 2012;11(11) 1579-91.

26. Sachdev P, Kalaria R, O'Brien J, Skoog I, Alladi S, Black SE, et al. Diagnostic criteria for vascular cognitive disorders: a VASCOG statement. Alzheimer Dis Assoc Disord. 2014;28(3):206-18. 